incomplete block, placebo-controlled, 2-way crossover study. Post hoc data analysis from patients who received both FP/ FORM doses is presented.

Methods 62 patients $\left(33 \mathrm{M}, 29 \mathrm{~F}\right.$; $=18 \mathrm{yrs}$; reversible $\mathrm{FEV}_{1}$ $=60 \%$ pred.) discontinued maintenance ICS medication for 2 3 wks; those showing a provocative dose of AMP producing a $20 \%$ decline in $\mathrm{FEV}_{1}\left(\mathrm{AMP} \mathrm{PD}_{20} \mathrm{FEV}_{1}\right)$ of $<60 \mathrm{mg}$ were randomised to receive 2 of 3 treatments (FP/FORM high-, low-dose or placebo) during 2 periods of $28 \pm 3$ days each, separated by 2 - 3wks. AMP challenges were performed pre-dose and repeated $12 \mathrm{~h}$ after last dose at the end of each treatment period. The difference in changes in AMP $\mathrm{PD}_{20} \mathrm{FEV}_{1}$ (day 1 vs day 28) between treatments were compared by an ANCOVA.

Results 15 patients were randomised to receive both high- and low-dose FP/FORM. The change in AMP $\mathrm{PD}_{20} \mathrm{FEV}_{1}$ was greater with FP/FORM high- compared with low-dose (LS means: high dose $=11 \mathrm{mg} ; 95 \%$ CI 4.3, 27.9; low dose $=4.6$ mg, 95\% CI 1.8, 11.8), with a statistically significant 2.4 fold difference in AMP $\mathrm{PD}_{20} \mathrm{FEV}_{1}$ (1.2 doubling doses) between doses (LS mean: 2.4; 95\% CI 1.3, 4.5; p = 0.012). FP/FORM was well-tolerated; only few (mild or moderate) AEs occurred. Conclusions A significant dose-response was found between low- and high-dose FP/FORM with the higher dose demonstrating a greater reduction in airway responsiveness to AMP.

\section{P167 EFFICACY AND SAFETY OF OMALIZUMAB IN REAL- WORLD CLINICAL PRACTICE IN INDIAN PATIENTS WITH ALLERGIC (IGE-MEDIATED) ASTHMA: ANALYSIS BY BASELINE SEVERITY OF ASTHMA}

'Z Udwadia, ${ }^{2} \mathrm{R}$ Narasimhan, ${ }^{3} \mathrm{VK}$ Ratnavelu, ${ }^{4} \mathrm{M}$ Kotnis; ${ }^{1} \mathrm{P}$ D Hinduja National Hospital and Medical Research Centre, Mumbai, India; ${ }^{2}$ Apollo Hospitals (Main), Chennai, India; ${ }^{3}$ Yashoda Super Specialty Hospital, Secunderabad, India; ${ }^{4}$ Novartis India Ltd, Mumbai, India

\subsection{6/thoraxjnl-2013-204457.318}

Omalizumab (OMA) is a humanised anti-immunoglobulin E (IgE) monoclonal antibody, indicated as add-on therapy for moderate-to-severe persistent allergic (IgE-mediated) asthma. Here, we report the interim results of a 52-week observational study of OMA in patients in India, stratified by baseline severity of asthma.

In this open-label, non-comparative, non-interventional study, patients (age $=12$ years) with moderate-to-severe persistent allergic asthma, inadequately controlled despite ICS + LABA (GINA step 4) treatment, were recruited. All patients were receiving OMA at baseline. Outcomes were assessed every 4 weeks, and included exacerbations, days missed at college or work, hospitalizations, and mean change (D) in $\mathrm{FEV}_{1}$, ACQ5 score, ACT score and oral corticosteroid (OCS) dose versus baseline. Adverse events were also recorded. Asthma severity was assessed at baseline, in accordance with GINA guidelines, and classified as either moderate (group 1) or severe (group 2). Data were analysed using chi-squared and paired t-tests. All parameters were compared between baseline and Week 28 post-OMA treatment.

To date, 100 patients have completed 28 weeks of follow-up (36 patients in group 1 and 64 in group 2). Results are presented in the Table. The proportion of patients with $=1$ exacerbation, missing any day at work/college and requiring hospitalisation decreased appreciably in both groups. There was also significant improvement in lung function and asthma control, and a reduction in OCS need. Overall, 5 patients $(5 \%)$ reported adverse events (AEs), of whom 2 (2\%) reported serious
AEs (SAEs). The most frequent non-serious AEs were gastrointestinal (GI) and nervous system disorders and were suspected to be related to omalizumab. GI, respiratory, thoracic and mediastinal SAEs were reported, but were not suspected to be related to omalizumab. All reported AEs and SAEs resolved with treatment. 28 weeks' treatment with omalizumab was associated with reductions in asthma exacerbations and OCS requirements, and improvements in lung function and asthma control, that were comparable between patients with moderate or severe asthma at baseline

\begin{tabular}{|c|c|c|c|c|c|c|}
\hline \multirow[t]{2}{*}{ Parameter } & \multicolumn{2}{|c|}{ Group $1(n=36)$} & \multicolumn{2}{|c|}{ Group $2(n=64)$} & \multirow{2}{*}{\multicolumn{2}{|c|}{$\begin{array}{l}\text { Group } 1 \text { vs. } 2 \\
\text { p-Value }\end{array}$}} \\
\hline & baseline & 28 weeks & baseline & 28 weeks & & \\
\hline $\begin{array}{l}\text { Patients with } \geq 1 \\
\text { exacerbation }\end{array}$ & $9.5 \%$ & $0.0 \%$ & $9.3 \%$ & $1.1 \%$ & 0.530 & \\
\hline $\begin{array}{l}\text { Patients missing any } \\
\text { day at work/college }\end{array}$ & $23.8 \%$ & $0.0 \%$ & $25.9 \%$ & $7.4 \%$ & 0.200 & \\
\hline \multirow[t]{2}{*}{ Hospitalization rate } & $19.0 \%$ & $0.0 \%$ & $27.8 \%$ & $0.0 \%$ & - & \\
\hline & $\begin{array}{l}\text { D vs. } \\
\text { baseline }\end{array}$ & p-Value & $\begin{array}{l}\text { D vs. } \\
\text { baseline }\end{array}$ & $\mathrm{p}$-Value & $\begin{array}{l}\text { Mean } \\
\text { difference }\end{array}$ & p-Value \\
\hline $\mathrm{FEV}_{1}(\mathrm{~L})$ & +1.1 & 0.000 & +1.0 & 0.000 & 0.1 & 0.244 \\
\hline ACQ5 score (composite) & -7.5 & 0.000 & -7.3 & 0.000 & -0.2 & 0.786 \\
\hline ACQ5 score (mean) & -1.5 & 0.000 & -1.5 & 0.000 & 0.0 & 0.981 \\
\hline ACT score(mean) & +9.4 & 0.000 & +10.2 & 0.000 & -0.8 & 0.396 \\
\hline OCS dose (mg/day) & $-11.3^{\dagger}$ & 0.002 & $-18.8^{\ddagger}$ & 0.000 & 7.5 & 0.099 \\
\hline
\end{tabular}

${ }^{\dagger} 13$ and ${ }^{\ddagger} 16$ patients were receiving OCS at baseline in group 1 and 2, respectively.

\section{P168 THE EFFECT OF FLUTICASONE PROPIONATE/ FORMOTEROL FUMARATE COMBINATION THERAPY ON QUALITY OF LIFE SCORES IN ASTHMA PATIENTS}

T Mclver, S Dissanayake; Mundipharma Research Limited, Cambridge, UK

\subsection{6/thoraxjnl-2013-204457.319}

Introduction The Asthma Quality of Life Questionnaire (AQLQ) is a validated questionnaire which measures the effect of asthma on patient's lives. AQLQ data from four phase III studies were pooled to assess how AQLQ scores are affected by treatment with fluticasone propionate (FP)/formoterol fumarate (FORM) in a single MDI (FP/FORM; flutiform) compared with other combination treatments.

Method AQLQ data from a pooled analysis of two phase III open-label studies in patients with mild-moderate/severe asthma [pool 1; FP/FORM $50 / 5$ or $125 / 5(\mathrm{n}=206)$ vs. FP $50+$ FORM 12 given together in separate inhalers and $\mathrm{FP} /$ salmeterol $50 / 25$ or $125 / 25(\mathrm{n}=206)]$, and a pooled analysis of two phase III double-blind studies in patients with moderate/severe asthma [pool 2; FP/FORM 250/10 ( $\mathrm{n}=294$ ) vs. FP 250 + FORM 12 given together in separate inhalers and budesonide/FORM 200/6 $(n=295)$ ] were analysed. AQLQ scores range from 1-7; a low score indicates the most severe impairment. Change in AQLQ from baseline to end of study was analysed using an ANCOVA. The proportion of subjects achieving a clinically relevant change of $=0.5$ units was analysed using a logistic regression model.

Results In pool 1, both groups had a similar increase in overall AQLQ score from baseline to end of study (0.635 in the FP/FORM group and 0.771 in the combination group) and the percentage of patients with a clinically relevant change in overall AQLQ score was $56 \%$ and $59 \%$, respectively. In pool 2, the mean increase in overall AQLQ score from baseline to end of study was 0.837 in the FP/ 
FORM group and 0.756 in the combination group, with $58 \%$ and $56 \%$ of patients experiencing a clinically relevant change in overall AQLQ score, respectively. The difference between the groups in each analysis was not statistically significant.

Conclusion FP/FORM has a similar effect on the quality of life of asthma patients as other combination treatments, with a similar improvement shown in each treatment group for both pools. Over $50 \%$ of patients in both treatment groups showed a clinically relevant change in AQLQ from baseline to end of study.

\section{REFERENCES}

1. Juniper EF, et al. Am J Respir Med 2002;1(6):435-40.

\section{P169 TIOTROPIUM IS EFFECTIVE IN PATIENTS WITH SEVERE ASTHMA WITHOUT EVIDENCE OF CHRONIC OBSTRUCTIVE PULMONARY DISEASE}

'Dmg Halpin, ${ }^{2}$ Ed Bateman, ${ }^{3} \mathrm{P}$ Moroni-Zentgraf, , ${ }^{3} \mathrm{M}$ Engel, ${ }^{3} \mathrm{H}$ Schmidt, ${ }^{4} \mathrm{Ham}$ Kerstjens; ${ }^{1}$ Royal Devon \& Exeter Hospital, Exeter, UK; ${ }^{2}$ University of Cape Town, Cape Town, South Africa; ${ }^{3}$ Boehringer Ingelheim Pharma GmbH \& Co KG, Ingelheim am Rhein, Germany; ${ }^{4}$ University of Groningen and the Department of Pulmonary Medicine and Tuberculosis, University Medical Center Groningen, and Groningen Research Institute for Asthma and COPD, Groningen, The Netherlands

\subsection{6/thoraxjnl-2013-204457.320}

Rationale Given the known effectiveness of tiotropium in chronic obstructive pulmonary disease (COPD) and the significant benefit observed in COPD patients with concomitant features of asthma, it is relevant to investigate whether patients included in the recent large trials of tiotropium in asthma can be confidently considered to have asthma alone.

Methods Baseline characteristics were analysed for patients enrolled in two replicate Phase III, randomised, double-blind, placebo-controlled, parallel-group studies of tiotropium in asthma patients symptomatic despite treatment with inhaled corticosteroids plus long-acting beta agonists (Kerstjens et al. NEJM 2012). The entry criteria were: age $18-75$ years; asthma diagnosed before the age of 40 years; $=5$-year history of asthma; score of $=1.5$ in the Asthma Control Questionnaire (ACQ) 7; and life-long non-smokers or ex-smokers ( $<10$ pack-years). Patients were also required to have persistent airflow limitation. Asthma diagnosis was confirmed in line with current Global Initiative for Asthma guidelines. Patients with a diagnosis of COPD or other lung disease were excluded from the studies.

Results 912 patients were enrolled: 456 received add-on treatment with tiotropium and 456 received placebo. Mean age of the study population was 53.0 years; $37.6 \%$ of patients were aged $=50$ years. Mean age at diagnosis of asthma was 22.7 (range 0-44) years. Median duration of asthma was 28.0 (range $5-72$ ) years, with $76.5 \%$ of patients having asthma for $=20$ years before enrolment. The majority of patients $(75.9 \%)$ were life-long non-smokers; $24.1 \%$ were ex-smokers with a median number of pack-years of only 5.0. Mean ACQ score was 2.6 (range 1-5). Mean immunoglobulin E was $1210 \mu \mathrm{mol} / \mathrm{L}$. The mean ( $\pm \mathrm{SD})$ bronchodilator response to salbutamol was $217 \pm 217 \mathrm{~mL}$

Conclusions The age of onset, duration of symptoms, lack of smoking, allergic status and bronchodilator response provide reasonable certainty that the patients enrolled in these studies had asthma and not COPD. Features compatible with COPD were thus more likely to reflect the effects of long-standing severe persistent asthma than the alternative diagnosis, and the efficacy demonstrated by tiotropium to represent improvement of asthma.

\section{P170 LONG-TERM EFFECTIVENESS OF OMALIZUMAB IN PATIENTS WITH SEVERE PERSISTENT ALLERGIC (IGE- MEDIATED) ASTHMA: UK CENTRE REAL-LIFE EXPERIENCE}

${ }^{1} \mathrm{AH}$ Mansur, , 'V Mitchell, 'L Alfridi, ${ }^{1} \mathrm{~J}$ Sullivan, ${ }^{2}$ I Kasujee; ${ }^{1}$ Severe \& Brittle Asthma Unit, Birmingham Heartlands Hospital, Birmingham, UK; ${ }^{2}$ Novartis Pharmaceuticals UK Limited, Frimley/Camberley, Surrey, UK

\subsection{6/thoraxjnl-2013-204457.321}

Omalizumab has been shown to be an effective add-on therapy for patients with uncontrolled severe persistent allergic (IgE-mediated) asthma. There has been a steady accumulation of evidence on long-term effectiveness of omalizumab; however, data on real-life outcomes beyond one year of treatment in a UK clinical setting is limited. In this analysis, data were compared for a number of patients from the Heartlands Hospital (Birmingham, UK), to determine if improvements were sustained with longer-term treatment. Patients $(n=45$, mean age 44.9 years, range: 19-69) received omalizumab for a mean duration of 49.3 months (range: 23-96). All patients with available data $(\mathrm{n}=18 / 45)$ showed a clinically relevant improvement in asthma control questionnaire (ACQ) scores post-omalizumab (mean ?ACQ: 2.27, range: 0.5-4.1; mean baseline ACQ: 4.1, range: 3.7-4.7). In patients on oral corticosteroids (OCS) vs patients not on OCS (at baseline), improvements were greater: ACQ of patients on OCS at baseline was 4.1 and 1.6 post treatment $v s 4.0$ at baseline and 2.7 post treatment. Mean OCS dose reduced pre- to post-omalizumab: 30.5 to $7 \mathrm{mg}$ /day. Reductions in hospital admissions/bed days were seen post-treatment (figure). There were also reductions in work/school days missed in 17/19 patients; the other 2 patients showing no change. Overall mean $\mathrm{FEV}_{1}$ was improved in the majority of patients with available data (17/20). Results from this real-life follow-up study demonstrate that improved outcomes in patients with severe allergic asthma are sustained with longer-term omalizumab therapy.

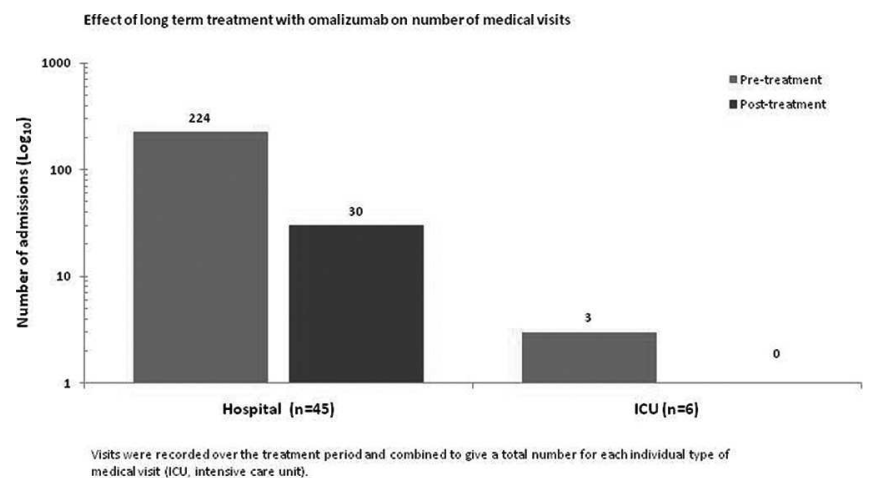

Abstract P170 Figure 1.

\section{P171 EFFICACY AND SAFETY OF BRONCHIAL THERMOPLASTY IN CLINICAL PRACTICE: EARLY RESULTS FROM A NATIONAL REGISTRY}

${ }^{1} \mathrm{~J}$ Burn, ${ }^{1} \mathrm{Aj}$ Sims, ${ }^{1} \mathrm{Dr}$ Bousfield, ${ }^{2} \mathrm{H}$ Patrick, ${ }^{3} \mathrm{~S}$ Welham, ${ }^{4} \mathrm{Lg}$ Heaney; ${ }^{1}$ The Newcastle upon Tyne Hospitals NHS Foundation Trust (on behalf of the British Thoracic Society (BTS) Difficult Asthma Network)., Newcastle upon Tyne, UK; ${ }^{2}$ National Institute for Health and Care Excellence (on behalf of the British Thoracic Society (BTS) Difficult Asthma Network.), London, UK; ${ }^{3}$ British Thoracic Society (on behalf of the British Thoracic Society 